\title{
High-frequency ultrasound for monitoring changes in liver tissue during preservation
}

\author{
Roxana M Vlad $^{1}$, Gregory J Czarnota ${ }^{2,4}$, Anoja Giles ${ }^{1,3}$, \\ Michael D Sherar ${ }^{1,3,5}$, John W Hunt ${ }^{1,3}$ and Michael C Kolios ${ }^{1,4}$ \\ ${ }^{1}$ Department of Medical Biophysics, University of Toronto, Toronto, Ontario, Canada \\ 2 Department of Radiation Oncology, University of Toronto, Toronto, Ontario, Canada \\ ${ }^{3}$ Ontario Cancer Institute, Toronto, Ontario, Canada \\ ${ }^{4}$ Department of Mathematics, Physics and Computer Science, Ryerson University, Toronto, \\ Ontario, Canada \\ ${ }^{5}$ Department of Oncology, University of Western Ontario, London, Ontario, Canada \\ E-mail: vroxana@uhnres.utoronto.ca
}

Received 21 August 2004, in final form 4 November 2004

Published 23 December 2004

Online at stacks.iop.org/PMB/50/197

\begin{abstract}
Currently the only method to assess liver preservation injury is based on liver appearance and donor medical history. Previous work has shown that high-frequency ultrasound could detect ischemic cell death due to changes in cell morphology. In this study, we use high-frequency ultrasound integrated backscatter to assess liver damage in experimental models of liver ischemia. Ultimately, our goal is to predict organ suitability for transplantation using high-frequency imaging and spectral analysis techniques. To examine the effects of liver ischemia at different temperatures, livers from Wistar rats were surgically excised, immersed in phosphate buffer saline and stored at 4 and $20{ }^{\circ} \mathrm{C}$ for $24 \mathrm{~h}$. To mimic organ preservation, livers were excised, flushed with University of Wisconsin (UW) solution and stored at $4{ }^{\circ} \mathrm{C}$ for $24 \mathrm{~h}$. Preservation injury was simulated by either not flushing livers with UW solution or, before scanning, allowing livers to reach room temperature. Ultrasound images and corresponding radiofrequency data were collected over the ischemic period. No significant increase in integrated backscatter $(\sim 2.5 \mathrm{dBr})$ was measured for the livers prepared using standard preservation conditions. For all other ischemia models, the integrated backscatter increased by $4-9 \mathrm{dBr}$ demonstrating kinetics dependent on storage conditions. The results provide a possible framework for using high-frequency imaging to non-invasively assess liver preservation injury.
\end{abstract}

(Some figures in this article are in colour only in the electronic version) 


\section{Introduction}

Ultrasound has become an important imaging modality in the medical field because it is safe, rapid, non-invasive, and relatively inexpensive. A transducer emits an ultrasound signal and as the sound waves propagate through tissues, part of the signal is scattered back towards the transducer from the acoustic inhomogeneities encountered. The ultrasonic scattering process in biological tissues is primarily affected by the size and the acoustic impedance of tissue scattering structures. Ultrasonic tissue characterization techniques are based on the premise that disease processes alter physical characteristics of tissue such as compressibility, density and scatterer geometry, and these alterations cause observable changes in acoustic scattering properties. Thus, spectrum analysis of backscattered pressure pulses propagated back to the transducer can provide information on tissue abnormalities such as the presence of cancer (Ursea et al 1998), cardiomyopathy, ischemia and myocardial infarction (Barzilai et al 1990, Miller et al 1985, O'Donnell et al 1981, Mimbs et al 1981) and liver disease (Lizzi et al 1988, King et al 1985).

High-frequency ultrasound (HFU) offers resolution in the range 20 to $50 \mu \mathrm{m}$, the approximate size of cells, with the aim of providing information typically available only from biopsy samples. High-frequency ultrasound (20 to $60 \mathrm{MHz})$ experiments using packed acute myeloid leukaemia (AML) cells treated with an apoptosis inducing drug have shown an increase of signal amplitude by 9-13 dBr (Czarnota et al 1997, 1999, Kolios et al 2002). The most striking histological features in the treated cells were nuclear condensation and fragmentation in addition to cell shrinkage, classical features of apoptotic cell death. If the same type of cells were left to die at room temperature by the withdrawal of nutrients for at least $5 \mathrm{~h}$, an increase in HFU integrated backscatter by $6 \mathrm{dBr}$ would be measured concomitantly with cell swelling and cytoplasmic vacuolization, features of oncotic cell death (commonly referred to as necrosis). With HFU from 20 to $60 \mathrm{MHz}$ individual cells cannot be resolved, however, changes in the intensity of integrated backscatter from cell ensembles can be observed, as well as changes from tissue undergoing structural damage (Czarnota et al 1997, 1999, Kolios et al 2002, 2003). Therefore, HFU may constitute a potential technique to assess organ injury before the transplantation procedure, since tissue damage that cannot be easily assessed with conventional procedures may occur following preservation.

The standard technique for liver allograft preservation is to flush liver with preservation solution and store it at $4{ }^{\circ} \mathrm{C}$. Advances in preservation methods allow liver preservation for up to $24 \mathrm{~h}$ (Belzer et al 1992). However, such methods are limited, with irreversible injury occurring after 8-24 h of human livers cold storage (Strasberg et al 1988, 1992). Clinical practice remains restricted not only by the quality and the number of donor organs available but also due to the lack of methods to assess whether the organ will function properly after transplantation. For human organ transplants, conventional liver function tests are based on donor data including age, body weight and medical history. Significant efforts have been made to assess donor grafts by evaluating markers of microvascular injury or different aspects of liver function including protein synthesis, drug metabolism, bile secretion and high-energy phosphate production (Shaked et al 1997, St Peter et al 2002, Vilca et al 2000). Currently, no method seems better than conventional liver function tests and liver graft appearance, as assessed by visual inspection, in deciding whether to use a graft in clinical practice. In general, the decision to use a preserved organ for transplantation is proven right, only retrospectively, if the recipient is discharged safely from hospital after transplant (Vilca et al 2000). Liver graft injury may be divided into three interrelated components: pre-preservation injury that is related to donor's medical history, preservation and reperfusion injury (Strasberg et al 1992), all of which are critical in establishing whether a graft will function properly after transplant. 
The preservation period sets the stage for injury manifested upon reperfusion. Despite this, there are no validated means of predicting outcome on the basis of biochemical or other tests.

Total ischemia occurs during organ preservation and is produced by the cessation of blood flow resulting in the combined effects of anoxia, lack of metabolic substrates and the absence of tissue perfusion. In the absence of organ preservation, total ischemia results in ion transport deregulation, cell swelling and finally death of the affected region in a period varying from minutes to hours. Ischemic death is dependent on temperature, the rate of anaerobic glycolysis, availability of stored substrate (usually in the form of glycogen) and other undetermined factors (Trump and Cowley 1982).

In this study, we propose a novel non-invasive method to assess structural changes in liver tissue following preservation injury. We hypothesize that the changes in HFU integrated backscatter in liver ischemia are related to the changes in size and acoustical properties of the cell induced by osmotic stress following adenosine triphosphate $\left(\mathrm{ATP}^{6}\right)$ depletion (Litniewski and Bereiter 1990, Luers et al 1991).

\section{Methods}

\subsection{Organ preparation}

Wistar rats (125-150 g) were euthanized by exposure to $100 \% \mathrm{CO}_{2}$ for up to $5 \mathrm{~min}$ and livers were immediately surgically excised. Livers $(n=12)$ were then immersed in phosphate buffer saline (PBS) and stored at $4{ }^{\circ} \mathrm{C}$ for $24 \mathrm{~h}(n=2)$ or left at room temperature $(n=10)$ for up to 10 or $24 \mathrm{~h}$. In preservation experiments, livers $(n=4)$ were surgically excised, flushed with 40 to $60 \mathrm{ml}$ of University of Wisconsin (UW) solution through the portal vein and stored at $4{ }^{\circ} \mathrm{C}$ for $24 \mathrm{~h}$. Preservation injury was simulated by simply storing the organs $(n=2)$ in UW solution without flushing them or flushing them $(n=2)$ with the preservation solution and, allowing them to re-warm at room temperature for at least $30 \mathrm{~min}$ before each ultrasonic analysis. These last two livers were consecutively re-warmed from 4 to $20{ }^{\circ} \mathrm{C}$ for ten times during the storage period of $24 \mathrm{~h}$.

\subsection{Microscopy}

Samples were saved for Haematoxylin and Eosin (H\&E) and electron microscopy (EM) staining by fixing them for $24 \mathrm{~h}$ in $10 \%$ formaldehyde for $\mathrm{H} \& \mathrm{E}$ staining and in $2.5 \%$ glutardehide at $8{ }^{\circ} \mathrm{C}$ for EM staining.

\subsection{Ultrasound data acquisition and spectral analysis}

High-frequency ultrasound backscatter images and the corresponding radiofrequency data were collected as a function of time during ischemia. A VS-40B ultrasound device (VisualSonics Inc., Toronto, Canada), employing a focused $f / 3$ transducer with operating frequency of $40 \mathrm{MHz}, 3 \mathrm{~mm}$ transducer diameter and a $-6 \mathrm{~dB}$ bandwidth of 25 to $55 \mathrm{MHz}$ was used. Data were collected within the depth of field of the transducer focal zone $(2.5 \mathrm{~mm})$. This range of frequencies allowed ultrasound wavelength of 30 to $60 \mu \mathrm{m}$ and a penetration depth of $3 \mathrm{~mm}$ in liver tissue. Homogeneous regions free of visible blood vessels were selected from B-mode images by visual inspection. Ultrasound signals were acquired from five different planes containing 30-50 scan lines each separated by one beam-width $(0.16 \mathrm{~mm})$ and stored digitally at a sampling rate of $500 \mathrm{MHz}$. The regions of interest chosen

6 ATP is required to transport and to store chemical energy within cells. 
for further analysis were 4 to $8 \mathrm{~mm}$ wide and $1 \mathrm{~mm}$ deep. These were chosen to be under but close to the organ surface to avoid specular reflections and minimize signal attenuation. Radiofrequency data from each bracketed line segment was multiplied by a Hamming weighting function to suppress spectral lobes, and the Fourier transform was computed. The squared magnitudes of the resultant spectra were averaged and divided by the power spectrum computed from a flat quartz calibration target in order to calculate the normalized backscatter power (NBP) expressed in $\mathrm{dBr}$. This procedure removed system and transducer transfer functions and provided a common reference for data collected with various transducers (Lizzi et al 1983, 1997).

The organs that required storage and data acquisition in cold were scanned on an ice bath. The tissue temperature was continuously measured during scanning with a digital thermometer. The temperature variation during scanning was between 4 to $8{ }^{\circ} \mathrm{C}$.

\subsection{Compensation for temperature and solution-dependent attenuation}

$\mathrm{UW}^{7}$ solution is a viscous fluid containing ingredients with a relatively high molecular mass. This results in higher ultrasound absorption of UW solution compared to PBS (absorption properties close to distilled water). In these experiments, the livers were scanned in UW solution and PBS at 4 and $20{ }^{\circ} \mathrm{C}$. Attenuation coefficients calculated for water at $40 \mathrm{MHz}$ were $6.5 \mathrm{~dB} \mathrm{~cm}^{-1}$ at $4{ }^{\circ} \mathrm{C}$ and $3.5 \mathrm{~dB} \mathrm{~cm}^{-1}$ at $20{ }^{\circ} \mathrm{C}$ (Pinkerton 1949). To compensate for greater attenuation at lower temperatures and absorption characteristics of the different storage solutions, calibrations were carried out with the reference taken at the glass quartz interface in PBS/UW solution at 4 and $20^{\circ} \mathrm{C}$. Figure 1 illustrates the pulse amplitude and power spectrum in the focal zone of the transducer at different temperatures in PBS and UW solution. The importance of proper normalization is illustrated in figure 2. For two fresh excised livers, the first liver immersed in UW solution at $4{ }^{\circ} \mathrm{C}$ and the second immersed in PBS at $20{ }^{\circ} \mathrm{C}$, the error introduced by normalizing both spectra with the same reference was corrected by adapting the calibration target to the solution and temperature employed in the experiment. In figure 2 , it is shown that without proper normalization the data cannot be compared between samples analysed in different experimental conditions (lines a and c). When the appropriate normalization is carried out (lines a and b) the resulting NBP values were comparable at $0 \mathrm{~h}$.

\section{Results}

In order to demonstrate the efficacy of high-frequency ultrasound to detect tissue structural changes at various conditions, four different liver ischemic conditions were imaged: warm and cold ischemia, standard preservation and simulated preservation injury.

\subsection{Warm and cold liver ischemia}

The purpose of the warm ischemia experiments was to provide an understanding of how ischemic cell structural changes result in ultrasound backscatter variations during severe tissue injury. For these livers, it was possible to average integrated backscatter values measured for each liver at the same time point as shown in figure 3 . The integrated backscatter peaks at 1 , 2,3 and $8 \mathrm{~h}$ for the remaining four livers with a maximum increase of integrated backscatter between $4.5-7.6 \mathrm{dBr}$. The averaged maximum increase of integrated backscatter was $\sim 6 \mathrm{dBr}$ for all ten livers immersed in PBS and stored at $20^{\circ} \mathrm{C}$ (table 1).

7 UW solution composition: potassium lactobionate $100 \mathrm{mM}, \mathrm{KH}_{2} \mathrm{PO}_{4} 25 \mathrm{mM}, \mathrm{MgSO}_{4} 5 \mathrm{mM}$, raffinose $30 \mathrm{mM}$, adenosine $5 \mathrm{mM}$, glutathine $3 \mathrm{mM}$, allopurinol $1 \mathrm{mM}$, hydroxyethyl starch $50 \mathrm{~g} \mathrm{~L}^{-1}$. 

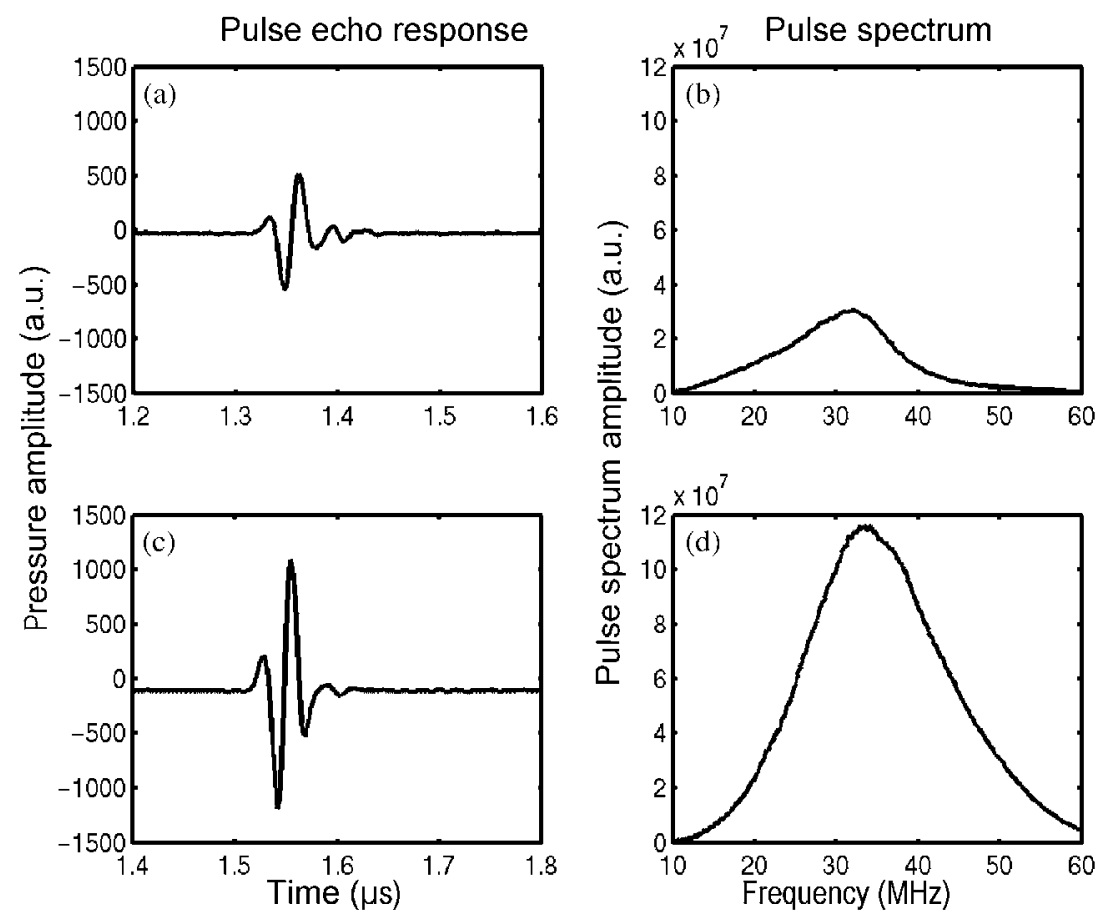

Figure 1. Pulse echo response and pulse spectrum for the $f / 3$ transducer with an operating frequency of $40 \mathrm{MHz}$ : (a), (b) in UW solution at $4{ }^{\circ} \mathrm{C}$; (c), (d) in PBS at $20{ }^{\circ} \mathrm{C}$. Scales are comparable for (a), (c) and (b), (d). Data are not shown for UW solution at $20^{\circ} \mathrm{C}$ and PBS at $4{ }^{\circ} \mathrm{C}$.

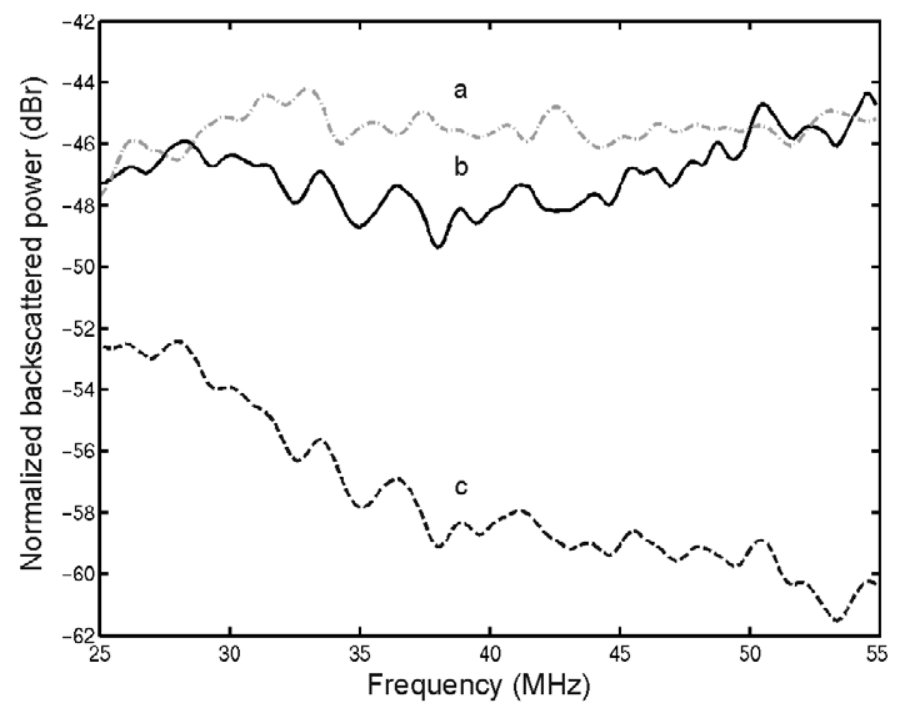

Figure 2. Calibration corrections. Normalized backscatter power for: (a) liver immersed in PBS at $20{ }^{\circ} \mathrm{C}$ normalized with the spectrum from a flat quartz in PBS at $20^{\circ} \mathrm{C}$; (b) liver immersed in UW solution at $4{ }^{\circ} \mathrm{C}$ normalized with the spectrum from a flat quartz in UW solution at $4{ }^{\circ} \mathrm{C}$; (c) liver immersed in UW solution at $4{ }^{\circ} \mathrm{C}$ normalized with the spectrum from a flat quartz in PBS at $20^{\circ} \mathrm{C}$. 


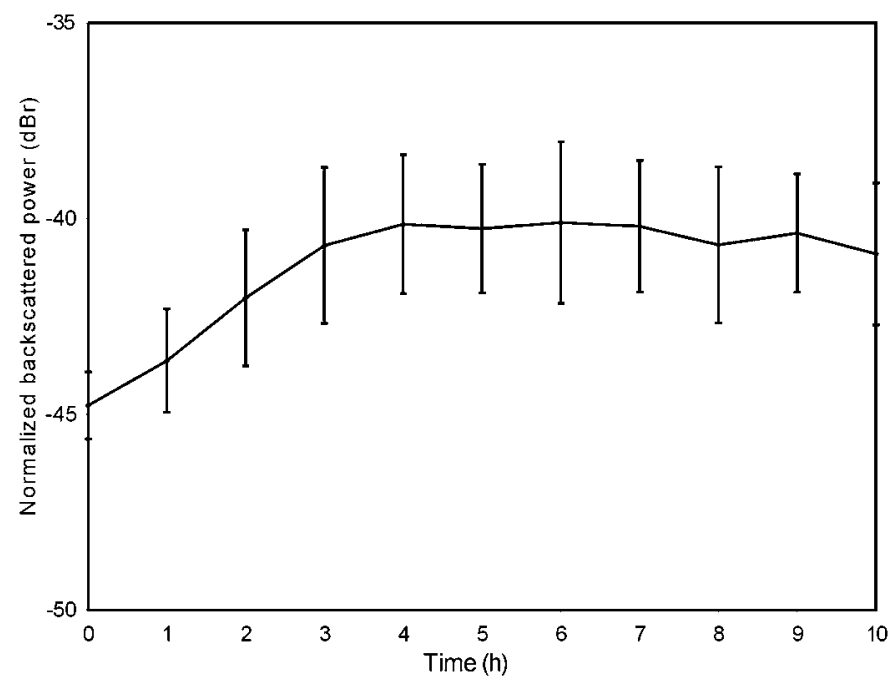

Figure 3. Normalized backscatter power averaged for six different livers during 1 to $10 \mathrm{~h}$ of liver ischemia at $20^{\circ} \mathrm{C}$. The error bars represent the standard deviation of normalized backscatter power.

Table 1. Averaged values of maximum increase in integrated backscattered ultrasound for different experimental conditions.

\begin{tabular}{|c|c|c|c|c|c|}
\hline \multirow{3}{*}{$\frac{\text { Experimental model }}{\text { Flushed with UW solution }}$} & \multicolumn{2}{|c|}{ Livers stored in PBS } & \multicolumn{3}{|c|}{ Livers stored in UW solution } \\
\hline & \multirow{2}{*}{$\begin{array}{l}\text { Warm } \\
\text { ischemia }\end{array}$} & \multirow{2}{*}{$\begin{array}{l}\text { Cold } \\
\text { ischemia }\end{array}$} & \multirow{2}{*}{$\begin{array}{l}\text { Preservation } \\
\text { Yes }\end{array}$} & \multicolumn{2}{|c|}{$\begin{array}{l}\text { Simulated preservation } \\
\text { injury }\end{array}$} \\
\hline & & & & No & Yes \\
\hline Number of livers analysed & $n=10$ & $n=2$ & $n=4$ & $n=2$ & $n=2$ \\
\hline Temperature of storage $\left({ }^{\circ} \mathrm{C}\right)$ & 20 & 4 & 4 & 4 & 4 \\
\hline Temperature during scanning $\left({ }^{\circ} \mathrm{C}\right)$ & 20 & $4-8$ & $4-8$ & $4-8$ & 20 \\
\hline $\begin{array}{l}\text { Maximum increase of integrated } \\
\text { backscatter averaged over the } \\
\text { number of analysed livers }(\mathrm{dBr})\end{array}$ & $6 \pm 1.07$ & $9 \pm 2.3$ & $2.5 \pm 1.47$ & $8 \pm 1.44$ & $4 \pm 1.71$ \\
\hline
\end{tabular}

Normalized backscatter spectra with corresponding ultrasonic images and representative histology of one liver ischemia are shown in figures 4 and 5. Normalized backscattered power values calculated from livers stored at room temperature and in cold are represented in figure 6 . The ultrasound backscatter amplitude increased between 0 and $6 \mathrm{~h}$ of warm ischemia as the cells underwent structural changes such as cell swelling, cytoplasm vacuolization in figure 5, mitochondrial swelling and nuclear envelope deformation in figure 7(a). After 6-10 $\mathrm{h}$ of liver storage at room temperature the tissue appeared necrotic. Imaging the organs stored at $20^{\circ} \mathrm{C}$ beyond $10 \mathrm{~h}$ does not have clinical relevance due to advanced liver tissue necrosis. However, two livers were imaged at later time points in order to observe ultrasound backscatter kinetics with advanced tissue necrosis as shown in figure 6 . With both warm and cold ischemia, integrated backscatter increased with the progression of tissue morphological changes up to a certain time point when it began to decrease depending on storage conditions (in this case temperature). The livers excised and stored in cold PBS demonstrated a progressive increase in backscattered ultrasound up to $10 \mathrm{~h}$ and a decrease after 20-22 h, 


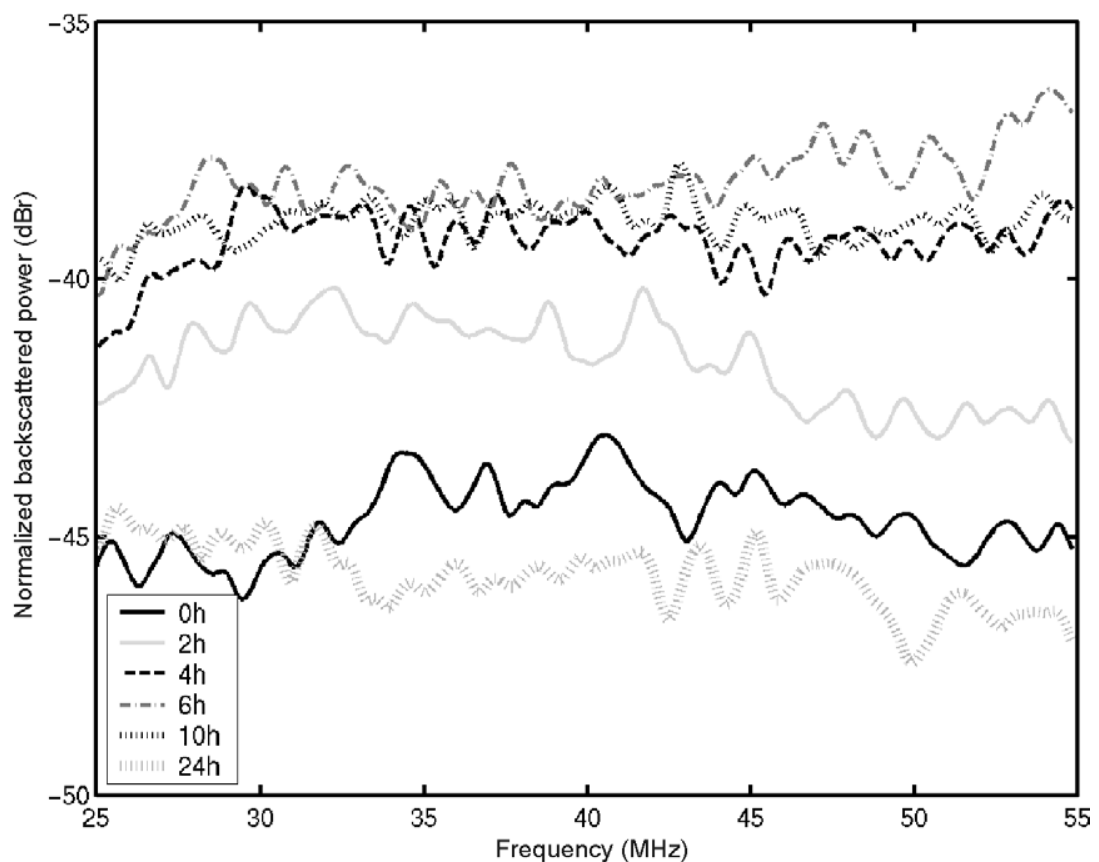

(a)

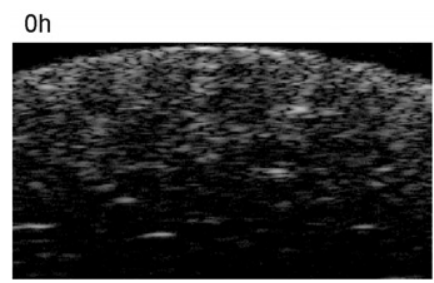

$2 \mathrm{~h}$
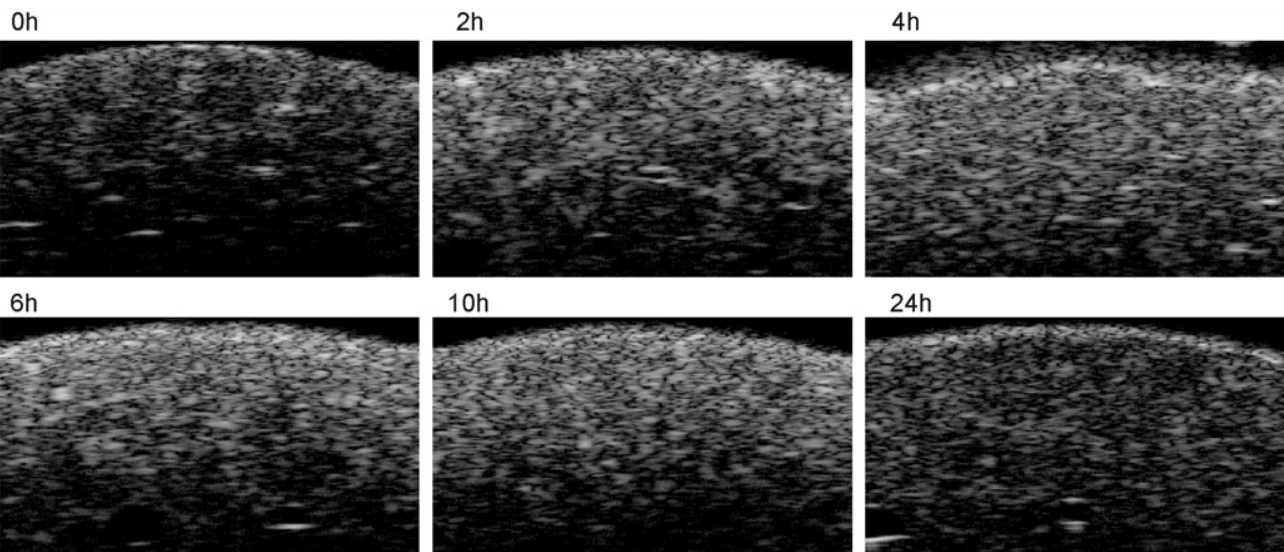

$10 \mathrm{~h}$

$24 \mathrm{~h}$
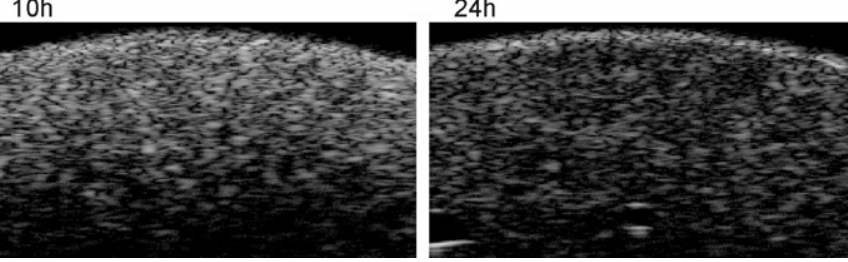

(b)

Figure 4. Representative normalized backscatter power spectra and ultrasonic images for one liver ischemia $\left(20^{\circ} \mathrm{C}\right), 0$ to $24 \mathrm{~h}$. (a) The maximum normalized backscatter power increase of $6.7 \mathrm{dBr}$ was measured after $6 \mathrm{~h}$ of liver storage at $20^{\circ} \mathrm{C}$. (b) Ultrasonic images $\left(2.5 \times 6 \mathrm{~mm}^{2}\right)$ with progressive increase in brightness from 0 to $6 \mathrm{~h}$.

whereas livers stored in warm PBS had the ultrasound backscatter increasing in the first 4-6 h, then remaining relatively steady up to $10 \mathrm{~h}$ and subsequently decreasing to the initial values around $24 \mathrm{~h}$. Structural changes of advanced tissue necrosis as shown in figures 7(b) and 8 were observed at later time points corresponding to a decrease in the backscattered ultrasound.

Histology collected from liver samples after $24 \mathrm{~h}$ of cold ischemia shows cell swelling (figure 8(a)), typical consequences of ion transport deregulation in liver ischemic hypothermia (Lockshin et al 1998, Trump and Cowley 1982, 1983). Electron microscopy (figure 8(b)) 
$\mathrm{Oh}$

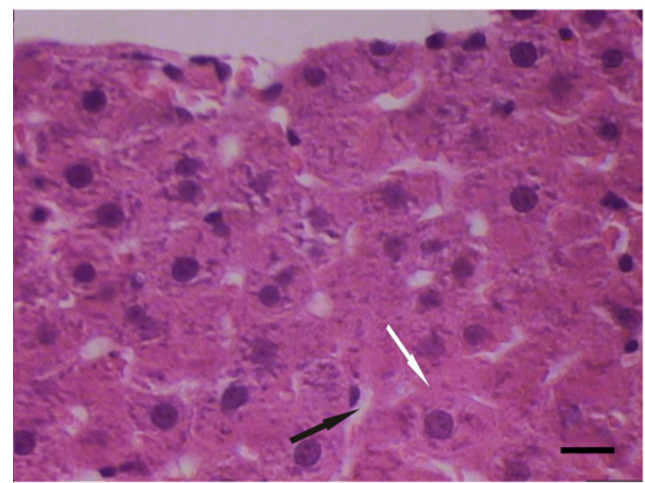

$4 \mathrm{~h}$

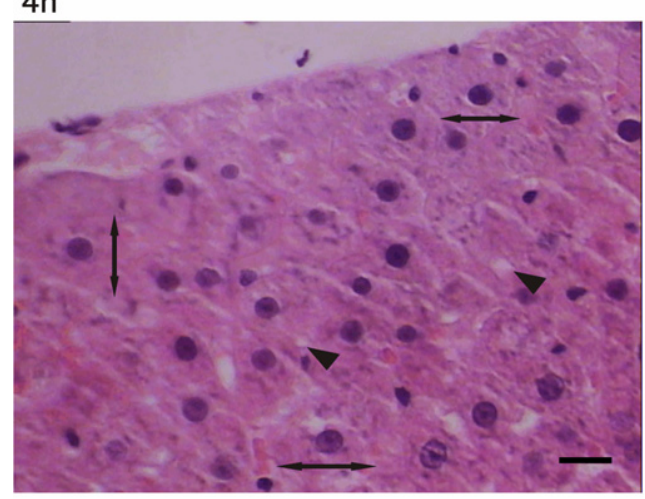

$10 \mathrm{~h}$

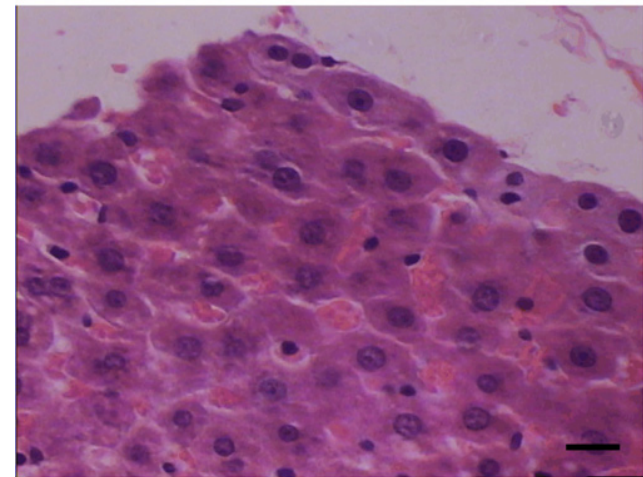

$2 \mathrm{~h}$

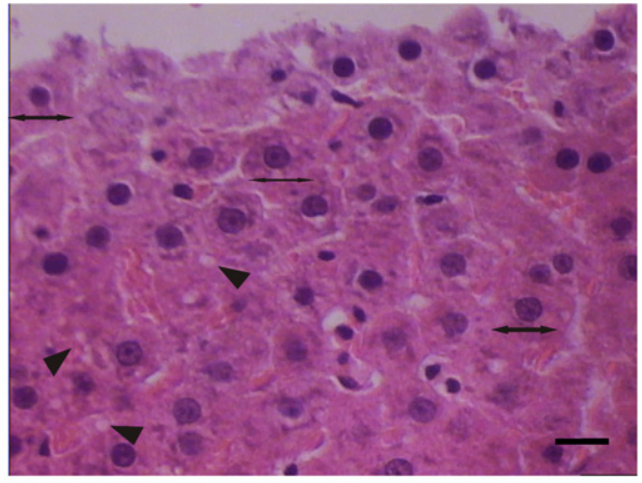

$6 h$

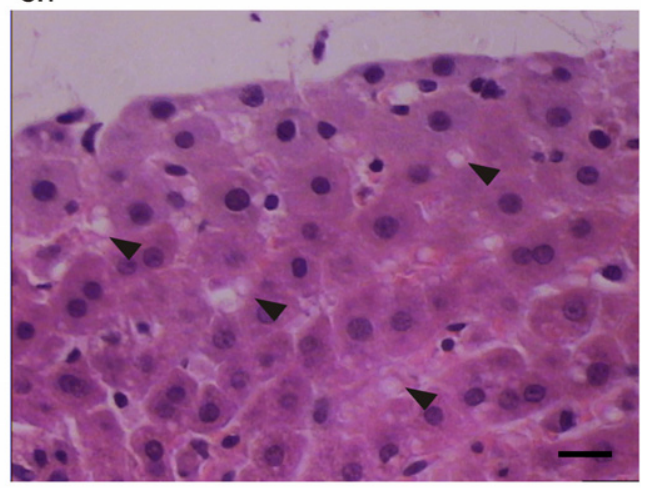

$24 \mathrm{~h}$

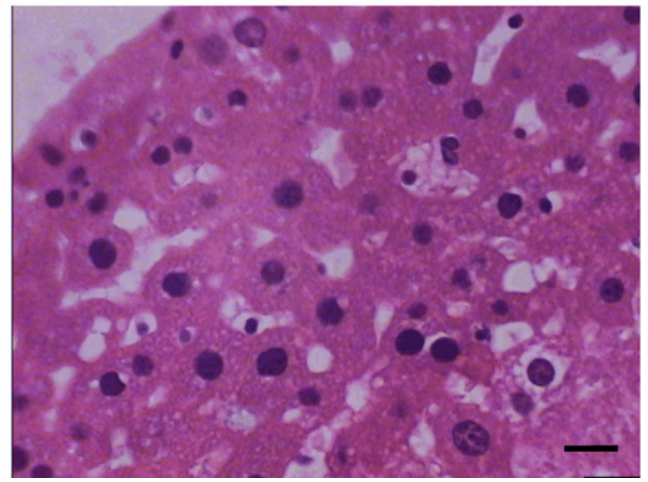

Figure 5. Haematoxylin \& Eosin staining of liver changes with ischemia $\left(20^{\circ} \mathrm{C}\right)$ illustrating liver's gradual damage from 0 to $24 \mathrm{~h}$. At $0 \mathrm{~h}$ liver with normal morphology, the arrows indicate one normal hepatocyte (white arrow) and sinusoid (black arrow). From 2 to $24 \mathrm{~h}$ the histology illustrates cytoplasmic vacuolization $(\bullet)$ and progressive changes in cell morphology such as cell swelling $(\leftrightarrow)$ at 2 and $4 \mathrm{~h}$. At $4 \mathrm{~h}$ an up to $30 \%$ increase in the cell size was estimated. Beginning with $6 \mathrm{~h}$, the cytoplasm becomes darker and more homogeneous indicating cell necrosis. The nuclei condensation and disrupted tissue morphology at $24 \mathrm{~h}$ are consistent with significant necrosis. The scale bar indicates $20 \mu \mathrm{m}$.

demonstrated further damage including cytoplasmic vacuolization, mitochondrial condensation and calcification, cellular features of necrosis in ischemic injury (Trump and 


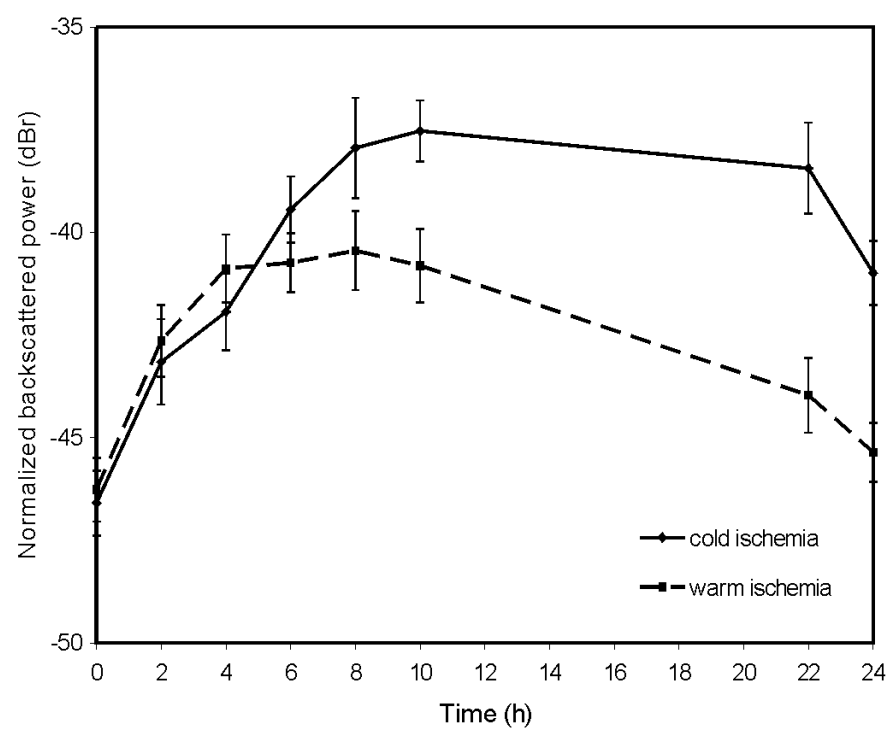

Figure 6. Averaged values ofnormalized backscatter power spectra of warm $(n=2)$ and cold $(n=2)$ liver ischemia from 0 to $24 \mathrm{~h}$. The error bars represent the normalized backscatter power (NBP) variations at different locations on the same liver. They also count for NBP variations with temperature changes during data acquisition. The standard deviations are calculated at one time point for each liver and averaged over the number of livers analysed.

Cowley 1982, 1983). In these experiments, because of ATP reduction and inhibition of ATP synthesis, cells most likely die by oncosis as opposed to apoptosis (Lockshin et al 1998, Jaeschke and Lemasters 2003) with a necrotic endpoint. Representative histological results of warm and cold ischemic livers as shown in figures 5, 7 and 8 illustrate morphological changes of cells undergoing oncosis including cell and mitochondrial swelling, cytoplasmic vacuolization, nuclear alteration and membrane disruption (Lockshin et al 1998, Kim et al 2003, Jaeschke and Lemasters 2003).

The maximum increase of integrated backscatter for organs stored at $4{ }^{\circ} \mathrm{C}, \sim 9 \mathrm{dBr}$, was higher than for organs stored at $20^{\circ} \mathrm{C}, \sim 6 \mathrm{dBr}$ in table 1 . These trends were reproducible and suggest different mechanisms of cell injury in cold and warm ischemia.

\subsection{Preservation and preservation injury}

Organs prepared after standard preservation conditions showed a slight increase in integrated backscatter of $\sim 2.5 \mathrm{dBr}$ (figure 9). To simulate injury, livers were not flushed but stored in UW solution at $4{ }^{\circ} \mathrm{C}$. Otherwise livers were flushed with UW solution, stored at $4 \mathrm{C}^{\circ}$ and before each ultrasonic analysis they were kept for $30 \mathrm{~min}$ at room temperature allowing the temperature to increase up to $20^{\circ} \mathrm{C}$.

Ultrasound backscatter increased in both types of simulated preservation injury. Cell structural damage after $24 \mathrm{~h}$ is shown in figure 9. The histology of livers prepared after standard preservation conditions (figure 9(a)) showed morphology still close to normal livers in figure 5 at $0 \mathrm{~h}$ whereas the histology of the simulated preservation injury showed cytoplasmic vacuolization and disrupted cell morphology such as larger sinusoidal spaces with the detachment of sinusoid lining cells that were rounded and positioned in the sinusoidal lumen in figures 9(b) and (c). For organs flushed with UW solution and scanned at $20{ }^{\circ} \mathrm{C}$ 


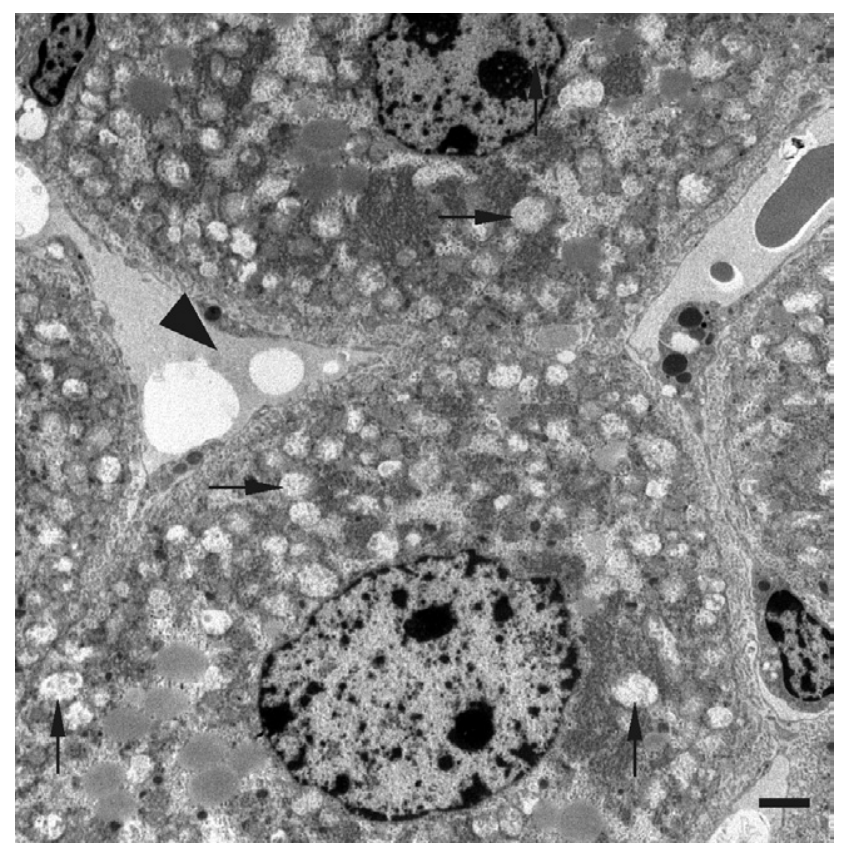

(a)

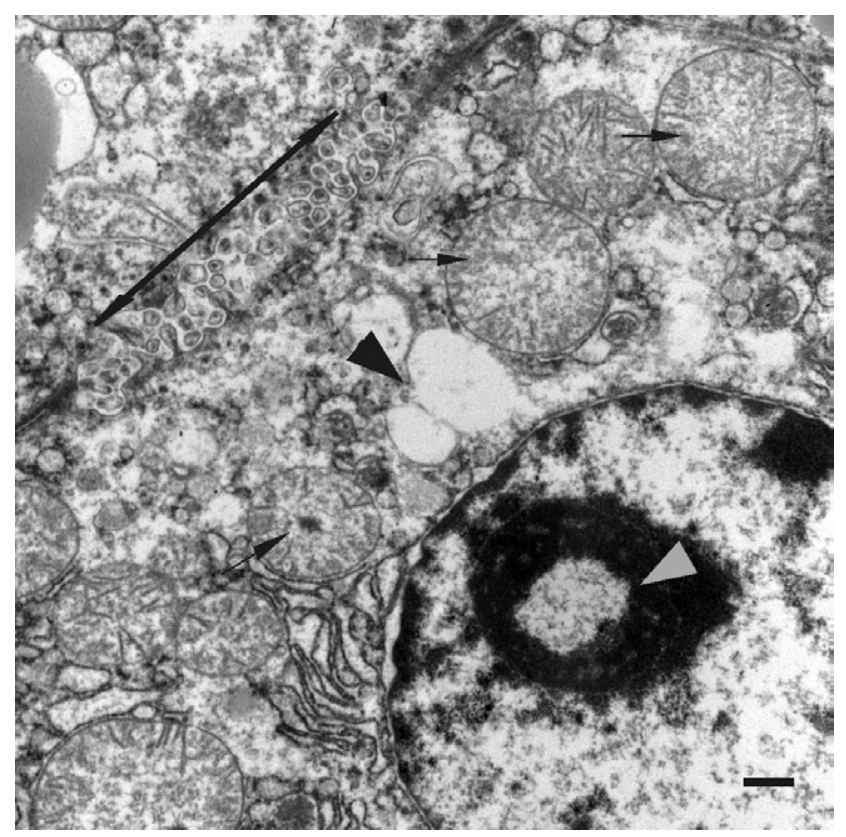

(b)

Figure 7. Electron microscopy staining of liver ischemia $\left(20^{\circ} \mathrm{C}\right)$. (a) $1 \mathrm{~h}$ liver warm ischemia with swollen mitochondria $(\rightarrow)$, vacuoles in sinusoidal spaces $(\rightarrow)$ and nuclear envelope deformation. Hepatocyte membranes seem still viable. (b) $10 \mathrm{~h}$ liver warm ischemia illustrating cell necrosis with vacuolization $(\triangleright)$ swollen mitochondria with cristae disruption and possible calcifications $(\rightarrow)$, clumped chromatin $(\bullet)$ and cell membrane alteration $(\leftrightarrow)$. Scale bars indicate $2 \mu \mathrm{m}$ (a) and $500 \mathrm{~nm}(\mathrm{~b})$. 


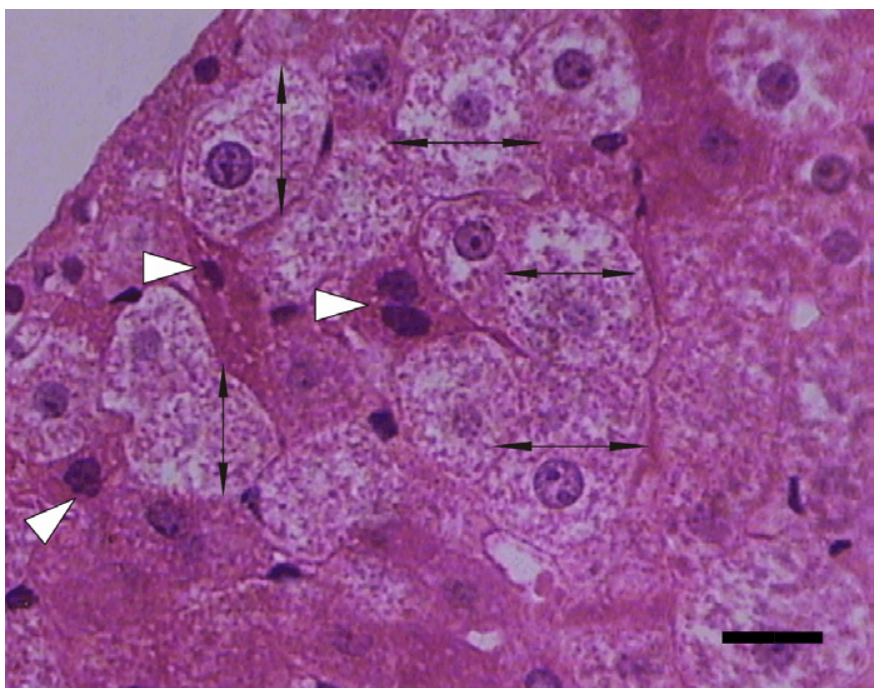

(a)

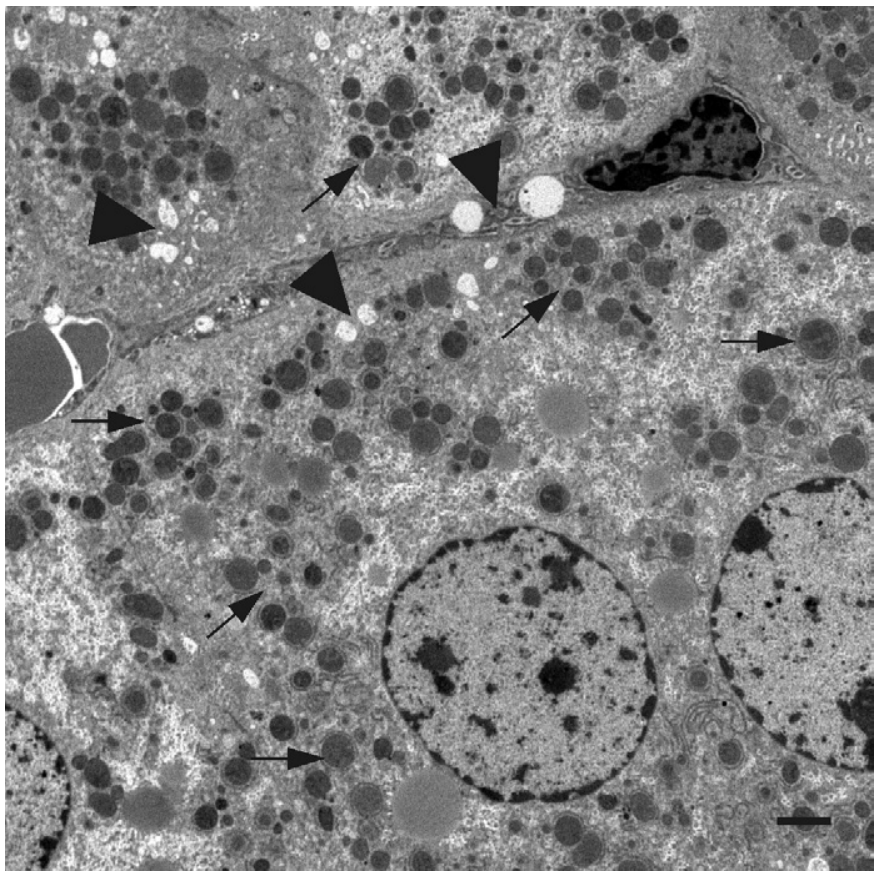

(b)

Figure 8. Haematoxylin \& Eosin and electron microscopy staining collected after $24 \mathrm{~h}$ of liver cold ischemia. (a) Cell necrosis $(\Delta)$ and cell swelling $(\leftrightarrow)$. At $24 \mathrm{~h}$ an up to $35 \%$ increase in cell size was estimated. (b) Vacuolization $(\checkmark)$ and extensive mitochondria condensation $(\rightarrow)$ illustrating cell oncotic necrosis. Scale bars indicate $20 \mu \mathrm{m}$ (a) and $2 \mu \mathrm{m}$ (b).

the liver histology showed features of tissue necrosis such as massive vacuolization, nuclear condensation and tissue morphology disruption. The integrated backscatter ultrasound decreased at later time points similar to the livers stored in PBS at $20{ }^{\circ} \mathrm{C}$ (figure 6). 


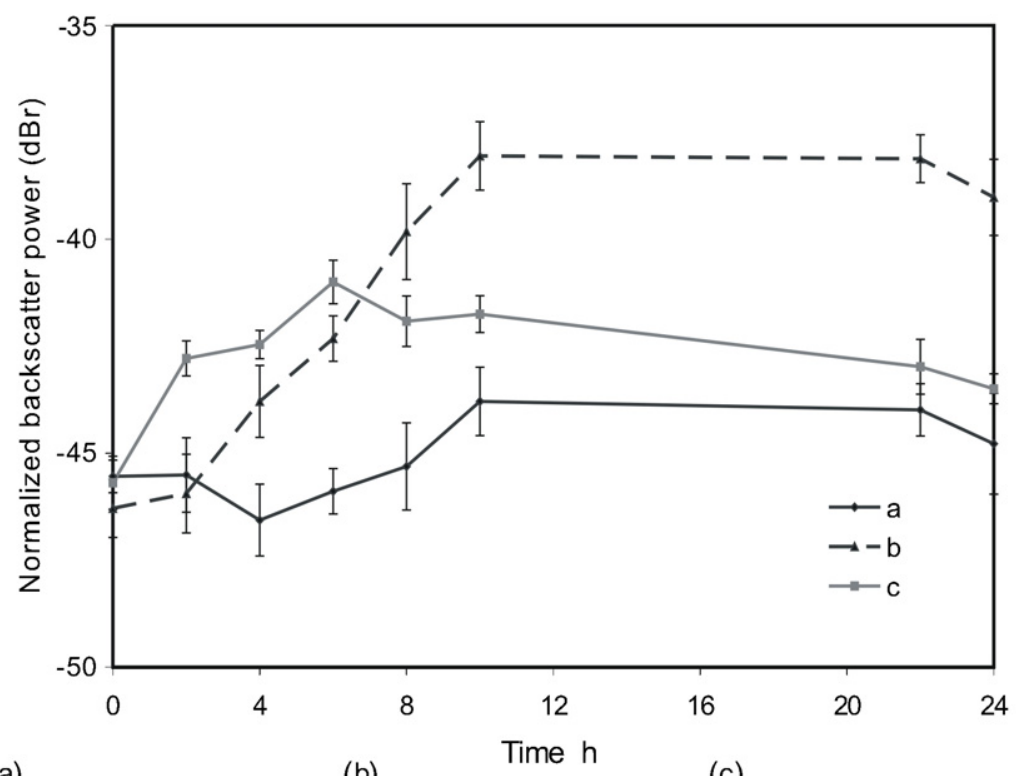

(a)

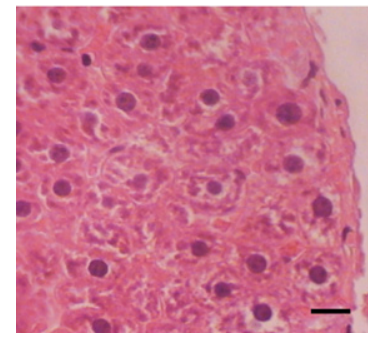

(b)

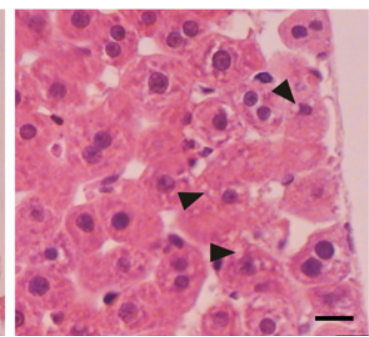

(c)

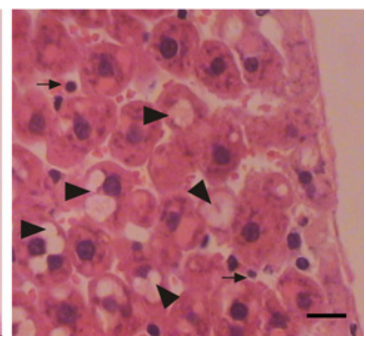

Figure 9. Normalized backscatter power represented as a function of storage period and Haematoxylin \& Eosin staining collected after $24 \mathrm{~h}$ ischemia for: (a) four livers preserved in standard preservation conditions with cell morphology close to normal; (b) two livers not flushed with UW solution but stored in preservation solution at $4{ }^{\circ} \mathrm{C}$ presenting changes in cell shape and cytoplasm vacuolization ( $)$; (c) two livers re-warmed before scanning up to room temperature with cytoplasm extensive vacuolization $(\downarrow)$, large sinusoidal spaces, detachment of sinusoid lining cells $(\rightarrow)$ and disrupted cell morphology. The scale bar indicates $20 \mu \mathrm{m}$.

\section{Discussion}

Previous studies have shown that high-frequency imaging and spectral analysis techniques may assess changes in cell structure following oncosis, apoptosis and cell mechanical structure manipulation like cell shrinking and swelling induced by osmotic stress in hypertonic/ hypotonic solutions (Czarnota et al 1997, 1999, Kolios et al 2002, 2003). This paper demonstrates that liver structural changes during preservation period are detectable using high-frequency ultrasound integrated backscatter. We have been able to demonstrate the ultrasonic detection of liver ischemic injury in different storage conditions including warm, cold ischemia and preservation injury.

Changes in the ultrasound backscatter are due to the changes in size, acoustic impedance and spatial distribution of ultrasound scatterers, all of which may be modified during our experiments. Since it is not known what predominantly scatters ultrasound in tissue, 
the correlation of measured variation in backscattered ultrasound to changes of scattering structures in liver histology is difficult.

The structure of the liver consists of predominantly hepatocytes which account for $80 \%$ of the liver volume (Gray et al 1995) interspersed with narrow white channels called sinusoids as shown in figure 4 at $0 \mathrm{~h}$. The hepatocytes have a diameter between 20 to $30 \mu \mathrm{m}$ and one or two nuclei with a diameter between 8 to $12 \mu \mathrm{m}$. These structures may act as ultrasound scatterers at the ultrasound wavelengths of 30 to $60 \mu \mathrm{m}$ employed in this work. At higher magnification using EM (figures 7 and 8(b)) are observed subcellular components such as mitochondria and nucleoli with diameters between 1 to $10 \mu \mathrm{m}$ that may act as Rayleigh scatterers. For Rayleigh scattering we expect an $f^{4}$ frequency dependence in normalized spectra of analysed livers instead of the dependence close to $f^{1}$ observed in these experiments (figure 4(a)). This suggests that the ultrasound wavelength approaches the size of the tissue inhomogeneities. Which anatomical components in liver tissue are responsible for ultrasonic scattering is an unresolved issue. Some investigators suggest that the cell nucleus is a strong source of ultrasonic scattering (Czarnota et al 1997, 1999, Kolios et al 2002) whereas others propose whole hepatic cells (Fei and Shung 1985).

Cell swelling, cytoplasm vacuolization and cytoskeleton alteration have been reported in the literature (Trump and Cowley 1982, Bilenko 2001) as the most common consequences of ischemic injury but these alterations also increased mechanical stiffness in the cell exposed to stress (Maksym et al 2003, Guilak et al 2004). Scanning acoustic microscopy studies (Bereiter-Hahn et al 1995, Luers et al 1991, Wagner et al 2001) on cells and cell-cytoskeleton isolated components measured variations of elasticity and viscoelasticity modulus during cellcytoskeleton polymerization and disruption. These findings suggest that cell mechanics depend on the properties of the cell-cytoskeleton and its interaction with associated proteins. Cell swelling, cytoplasm vacuolization and disruption of the sinusoidal lumen were the most striking cell injuries observable in the histology collected from liver samples in our study. These are the typical consequences of cell-cytoskeleton alteration (Lockshin et al 1998, Strange 1994, Trump and Cowley 1982, 1983 1991) and may potentially cause variations of tissue acoustic parameters in liver ischemic injury.

Considering that the spatial arrangement of scatterers may be responsible for variations in ultrasound backscatter (Hunt et al 1995), we studied the phase distribution calculated from backscattered ultrasound. For well-organized tissue such as liver we would expect the nonuniform phase distribution at $0 \mathrm{~h}$ to evolve to a uniform phase distribution at later time points in ischemia (Molthen et al 1997, Weng et al 1992). This would correlate with the deviations in scatterer spacing from a certain degree of regularity in healthy liver at $0 \mathrm{~h}$ to an increase in randomness due to tissue morphological alteration in liver ischemia (Molthen et al 1997). Studies of phase distribution on the liver ischemia models failed to demonstrate a reproducible trend from a regular phase distribution at $0 \mathrm{~h}$ to a uniform distribution at later time points (data not shown). The lack of evidence for changes in scatterer randomization leads us to hypothesize that the changes of cell acoustical properties are the consequences of cell structural alterations such as cell swelling, cytoplasm vacuolization and increase of cell membrane permeability. These cell alterations induce variations of intracellular and extracellular volumes and most likely modify the size, density and compressibility of scattering inhomogeneities.

An important principle of hypothermic organ storage is to slow those processes that require ATP and accumulate injury after ATP depletion occurs (Belzer and Southard 1988). Since low temperatures slow cell injury, the maximum increase of integrated backscatter was measured around $4-6 \mathrm{~h}$ at $20{ }^{\circ} \mathrm{C}$ and $10 \mathrm{~h}$ at $4{ }^{\circ} \mathrm{C}$. The composition of UW solution is designed to minimize hypothermic induced cell swelling (Belzer and Southard 1988) and 
thus to prevent cell injury produced by ATP depletion during preservation period. For livers prepared in standard preservation conditions and flushed with preservation solution, the tissue morphology was still close to normal and integrated backscatter did not show significant variations after $24 \mathrm{~h}$. For livers that were not flushed with UW solution, the protective effect of the solution was at most limited to the cells on the liver surface. High-frequency integrated backscatter increased after first hours of liver cold storage independently of the solution used to store them.

It has been shown that cells swell more at low temperatures (Trump and Cowley 1982, Lockhsin et al 1998) because cooling slows the metabolism and energy-dependent ion movements allowing passive movements to occur. The greater increase of integrated backscatter in livers stored in cold may be a consequence of greater cell swelling (up to $35 \%$ in livers stored at $4{ }^{\circ} \mathrm{C}$ versus $30 \%$ in livers stored at $20{ }^{\circ} \mathrm{C}$ in figures $5(4 \mathrm{~h}$ ) and $8(\mathrm{a})$ ) and presumably greater stress induced to cell structures such as the cell-cytoskeleton. Our measurements correlate quite well with other studies (Strasberg et al 1988) demonstrating that warm and cold ischemia result in different structural changes of the liver cell.

During oncotic necrosis, the cells approach physical-chemical equilibrium with the environment and involve degrading processes that result in the decomposition of organelles and interruption of the membrane continuity (Lockshin et al 1998). After $6 \mathrm{~h}$ of warm ischemia and $24 \mathrm{~h}$ of cold ischemia, progressive changes illustrating oncotic necrosis were observed in liver histology as shown in figures 5, 7(b) and 8. Cell structural changes in advanced tissue necrosis corresponded to a decrease in scattered ultrasound from liver tissue as shown in figure 6 . This may be a consequence of tissue decomposition induced by the necrotic process and thereby resulting in a reduction in the acoustic impedances of the scatterers.

To avoid bubble formation we used degassed PBS. UW solution is viscous fluid (figure 1) and less susceptible to bubble formation. Bubble formation in tissue is associated with the post-mortem process of autolysis ${ }^{8}$. The kinetics dependent on bubble formation in ex vivo tissue will most likely show an increase in backscatter as a function of tissue degradation whereas the kinetics of our experiment showed the backscatter increase in the first hours of ischemia (figures 3,6 and 9). The degrading processes illustrating late necrosis in liver histology (figures 5 (24 h), 7(b), 8(a) and (b)) and prone to produce bubbles were related to a decrease in integrated backscatter in these experiments.

The steep increase of integrated backscatter in the first hours of ischemia demonstrates the potential of high-frequency ultrasound to detect early structural changes in cell injury as results suggest. It is possible that this increase of integrated backscatter in early ischemia correlates up to a certain time point with reversible changes in liver morphology. Membrane disruption and appearance of calcium densities in mitochondria have been tied to irreversible events in liver preservation (Trump et al 1983). In this study, mitochondrial and membrane abnormalities were observed in EM staining after $10 \mathrm{~h}$ of organ storage at $20{ }^{\circ} \mathrm{C}$ in (figure 7(b)) and $24 \mathrm{~h}$ of organ storage at $4{ }^{\circ} \mathrm{C}$ (figure $8(\mathrm{~b})$ ) and corresponded to a decrease in the backscattered ultrasound.

\section{Conclusions}

This paper presents the results of our first studies aimed at detecting liver preservation injury. The work demonstrates that HFU imaging can detect liver ischemic injury induced by different storage conditions including temperature increase from 4 to $20^{\circ} \mathrm{C}$, improper preservation and hypothermia. These observations are not only limited to liver preservation injury as we have

8 Autolysis is the destruction of tissue cells by the action of certain enzymes. 
seen similar increases in backscatter with isolated kidneys in similar experiments (data not shown).

To make this technique practical in assessing liver preservation damage, the understanding of the specific changes in tissues that induce ultrasound backscatter variations and whether they are related to reversible or irreversible cell changes is required. The features of cell injury observed in this study such as cell swelling, disruption of the sinusoidal lumen and cytoplasmic vacuolization could be important factors leading directly to the onset of cell irreversible changes (Trump and Cowley 1982). These tissue alterations cannot be determined by visual inspection of liver before transplant. Thus, massive cell swelling could cause microvascular compression and perfusion defects which could farther exacerbate anoxia or prevent reperfusion of ischemic area and thereby facilitate parenchymal cell injury (Trump and Cowley 1982). The disruption of the sinusoidal lumen because of the endothelial cell damage, and compression of small vessels generate microcirculatory disorders that result in the no-reflow phenomenon during liver reperfusion in the recipient body (Bilenko 2001, Strasberg et al 1988, Trump and Cowley 1982).

Further research will determine whether the analysis of the integrated backscatter from the liver surface can be used as an indicator to assess organ suitability for transplantation. Our preliminary experiments showed that other transducers with greater penetration depth and working at $20 \mathrm{MHz}$ detected the same type of liver injury during preservation. After the considered refinements of the technique it might be applied successfully to assess organ injury before transplantation. The technique will present the advantage of the non-invasiveness, and furthermore it might detect early damage that cannot be assessed by visual inspection of liver appearance alone.

\section{Acknowledgments}

This work was supported by a grant from the Whitaker Foundation to Dr M C Kolios and a CFI/OIT grant that supported the ultrasound scanner. We gratefully thank Dr Ian Wanless (Director Canadian Liver Pathology Reference Centre) and Mr Yew Meng Heng for helpful assistance with histology analysis.

\section{References}

Barzilai B, Vered Z, Mohr G A, Wear K A, Courtois M, Sobel B E, Miller J G and Perez J E 1990 Myocardial ultrasonic backscatter for characterization of ischemia and reperfusion: relationship to wall motion Ultrasound Med. Biol. 16 391-8

Belzer F O, D'Alessandro A M, Hoffmann R M, Knechtle S J, Reed A, Pirsch J D, Kalayoglu M and Sollinger H W 1992 The use of UW solution in clinical transplantation A 4-year experience Ann. Surg. $215579-83$ discussion 584-5

Belzer F O and Southard J H 1988 Principles of solid-organ preservation by cold storage Transplantation $45673-6$

Bereiter-Hahn J et al 1995 Probing biological cells and tissues with acoustic microscopy Advances in Acoustic Microscopy ed A Briggs (New York: Plemium) pp 79-115

Bilenko M V 2001 Ischemia and Reperfusion of Various Organs Injury Mechanisms, Methods of Prevention and Treatment (Huntington, NY: Nova Science Publishers) pp 1-68

Czarnota G J et al 1997 Ultrasonic biomicroscopy of viable, dead and apoptotic cells Ultrasound Med. Biol. 23 961-5

Czarnota G J, Kolios M C, Abraham J, Portnoy M, Ottensmeyer F P, Hunt J W and Sherar M D 1999 Ultrasound imaging of apoptosis: high-resolution non-invasive monitoring of programmed cell death in vitro, in situ and in vivo Br. J. Cancer $\mathbf{8 1} 520-7$

Fei D Y and Shung K K 1985 Ultrasonic backscatter from mammalian tissues J. Acoust. Soc. Am. 78 871-6

Gray Henry, Bennister H L, Berry M M and Williams P L 1995 Gray's Anatomy: The Anatomical Basis of Medicine \& Surgery (London: Churchill Livingstone) 
Guilak F, Trickey W R and Vail T P 2004 The role of the cytoskeleton in the viscoelastic properties of human articular chondrocytes J. Orthop. Res. 22 131-9

Henson J H 1999 Relationship between the actin cytoskeleton and cell volume regulation Microsc. Res. Tech. 47 155-62

Hunt J W, Worthington A E and Kerr A T 1995 The subtleties of ultrasound images of an ensemble of cells: simulation from regular and more random distributions of scatterers Ultrasound Med. Biol. 21 329-41

Jaeschke H and Lemasters J J 2003 Apoptosis versus oncotic necrosis in hepatic ischemia/reperfusion injury Gastroenterology 125 1246-57

Kim J S, He L, Qian T and Lemasters J J 2003 Role of the mitochondrial permeability transition in apoptotic and necrotic death after ischemia/reperfusion injury to hepatocytes Curr. Mol. Med. 3 527-35

King D L, Lizzi F L, Feleppa E J, Wai P M, Yaremko M M, Rorke M C and Herbst J 1985 Focal and diffuse liver disease studied by quantitative microstructural sonography Radiology 155 457-62

Kolios M C, Czarnota G J, Lee M, Hunt J W and Sherar M D 2002 Ultrasonic spectral parameter characterization of apoptosis Ultrasound Med. Biol. 28 589-97

Kolios M C, Taggart L, Baddour R E, Foster F S, Hunt J W, Czarnota G J and Sherar M D 2003 An investigation of backscatter power spectra from cells, cell pellets and microspheres Ultrasonics Symp. pp 752-7

Litniewski J and Bereiter-Hahn J 1990 Measurements of cells in culture by scanning acoustic microscopy J. Microsc. 158 95-107

Lizzi F L, Astor M, Feleppa E J, Shao M and Kalisz A 1997 Statistical framework for ultrasonic spectral parameter imaging Ultrasound Med. Biol. 23 1371-82

Lizzi F L, Greenebaum M, Feleppa E J, Elbaum M and Coleman D J 1983 Theoretical framework for spectrum analysis in ultrasonic tissue characterization J. Acoust. Soc. Am. 73 1366-73

Lizzi F L, King D L, Rorke M C, Hui J, Ostromogilsky M, Yaremko M M, Feleppa E J and Wai P 1988 Comparison of theoretical scattering results and ultrasonic data from clinical liver examinations Ultrasound Med. Biol. $14377-85$

Lockshin Z T, Zahra Z and Jonathan L T 1998 When Cells Die (New York: Wiley-Liss) 57-97

Lockwood G R, Ryan L K, Hunt J W and Foster F S 1991 Measurement of the ultrasonic properties of vascular tissues and blood from 35-65 MHz Ultrasound Med. Biol. $17653-66$

Luers H, Hillmann K, Litniewski J and Bereiter-Hahn J 1991 Acoustic microscopy of cultured cells: distribution of forces and cytoskeletal elements Cell Biophys. 18 279-93

Maksym G N, Smith P G, Deng L and Fredberg J J 2003 Mechanical strain increases cell stiffness through cytoskeletal filament reorganization Am. J. Physiol. Lung Cell Mol. Physiol. 285 L456-L463 e-pub 18 Apr 2003

Miller J G, Perez J E and Sobel B E 1985 Ultrasonic characterization of myocardium Prog. Cardiovasc. Dis. 28 85-110

Mills J W, Schwiebert E M and Stanton B A 1994 Evidence for the role of actin filaments in regulating cell swelling J. Exp. Zool. 268 111-20

Mimbs J W, Miller J G and Sobel B E 1981 Detection of cardiomyopathic changes induced by doxorubicin based on quantitative analysis of ultrasonic backscatter Am. J. Cardiol. 47 1056-60

Molthen R C, Narayanan V M, Shankar P M, Reid J M, Genis V, Forsberg F, Halpern E J and Goldberg B B 1998 Using phase information in ultrasonic backscatter for in vivo liver analysis Ultrasound Med. Biol. 24 79-91

O’Donnell M, Mimbs J W, Bauwens D, Cohen R D, Miller J G and Sobel B E 1981 Effects of myocardial ischemia on quantitative ultrasonic backscatter and identification of responsible determinants Circ. Res. 49 89-96

Pinkerton J M M 1949 The absorption of ultrasonic waves in liquids and its relation to molecular constitution Proc. Phys. Soc. B 62 129-41

Shaked A, Nunes F A, Olthoff K M and Lucey M R 1997 Assessment of liver function: pre- and peritransplant evaluation Clin. Chem. 43 1539-45

St Peter S D, Imber C J and Friend P J 2002 Liver and kidney preservation by perfusion Lancet 359 604-13

Strange K 1994 Cellular and molecular physiology of cell Volume Regulation (Boca Raton, FL: CRC Press) pp 31-279

Strasberg S M, Clavien P A and Harvey P R 1992 Preservation and reperfusion injuries in liver allografts. An overview and synthesis of current studies Transplantation $\mathbf{5 3} 957-78$

Strasberg S M, McKeown C M, Edwards V, Phillips M J, Harvey P R and Petrunka C N 1988 Sinusoidal lining cell damage: the critical injury in cold preservation of liver allografts in the rat Transplantation 46 178-91

Trump F B and Cowley R A 1982 Pathophysiology of Shock, Anoxia and Ischemia (Baltimore, MD/London: William \& Wilkins) pp 10-143

Trump F B, Laufer A and Jones T R 1983 Cellular Pathobiology of Human Disease (New York/Stuttgart: Gustav Fischer) pp 5-117 
Ursea R, Coleman D J, Silverman R H, Lizzi F 1, Daly S M and Harrison W 1998 Correlation of high frequency ultrasound backscatter with tumor microstructure in iris melanoma Ophthalmology 105 906-12

Vilca Melendez H, Rela M, Murphy G and Heaton N 2000 Assessment of graft function before liver transplantation: quest for the lost ark? Transplantation 70 560-5

Wagner O, Schuler H, Hofmann P, Langer D, Dancker P and Bereiter-Hahn J 2001 Sound attenuation of polymerizing actin reflects supramolecular structures: viscoelastic properties of actin gels modified by cytochalasin $\mathrm{D}$, profilin and alpha-actinin Biochem. J. 355 771-8

Weng L, Reid J M, Shankar P M, Soetano K and Lu X-M 1992 Nonuniform phase distribution in ultrasound speckle analysis-part I and II: background and experimental demonstration IEEE Trans. Ultrason. Ferroelectr. Freq. Control 39 (3) 